\title{
Dixitalización do Mapa de capacidade produtiva dos solos de Galicia
}

Recibido: 16 maio 2014 / Aceptado: 18 novembro 2014

(C) IBADER- Universidade de Santiago de Compostela 2014
Resumo Neste traballo descríbese o proceso de preparación e posta a disposición do público da versión dixital do Mapa de Capacidade Produtiva dos Solos de Galicia, publicado orixinalmente en papel no ano 1984 baixo a dirección de Francisco Díaz-Fierros Viqueira e Fernando Gil Sotres. No momento de cumprir trinta anos desde a súa publicación, este mapa constitúe aínda o único traballo de avaliación da capacidade produtiva da terra con cobertura completa do territorio de Galicia. Con todo, as limitacións derivadas do formato en papel dificultaban considerablemente o seu uso. Confiamos en que a versión dixital que presentamos permita solventar parte destes problemas e ampliar o seu coñecemento e utilización entre a comunidade científica e técnica. Ao longo do texto trátase de situar en contexto a importancia do mapa orixinal e as razóns que motivaron a súa dixitalización, explicar o proceso seguido para a preparación da versión dixital, proporcionar información básica necesaria para futuros usuarios non familiarizados coa fonte orixinal, e finalmente presentar algúns datos resumo derivados do produto obtido.

Palabras clave mapa de solos, capacidade produtiva, sistemas de información xeográfica, ordenación territorial, Galicia

Abstract This paper describes the process of preparation and publication of a digital version of the Map of Soil

Eduardo José Corbelle Rico · David Vila García · Rafael Crecente Maseda

Laboratorio do territorio. Departamento de Enxeñería Agroforestal, Universidade de Santiago de Compostela

TIf: 982823324

E-mail: eduardo.corbelle@usc.es.

Francisco Díaz-Fierros Viqueira

Departamento de Edafoloxía e Química Agrícola, Universidade de Santiago de Compostela
Capability of Galicia, originally published as a book in 1984 by Francisco Díaz-Fierros Viqueira and Fernando Gil Sotres. Although thirty years have passed since its publication, this map still stands as the only available source about soil capability covering the whole territory of Galicia. Nevertheless, limitations imposed by the original publication format (hardcopy) posed a significant obstacle for its use. We believe that the digital version presented in this paper will help users to overcome part of these shortcomings and allow the map to be used by a wider cross-section of the scientific and planning communities. This text is aimed to place the map in context, expand on the reasons for the preparation of a digital version, explain the procedures followed in the process, provide basic information for its future users, and present some summarizing data processed from the final product.

Key words soil maps, soil capability, geographic information systems, planning, Galicia

\section{Introdución}

O solo, a capa superficial da cortiza terrestre que sustenta boa parte da vida no planeta, é un recurso natural limitado. A súa taxa de renovación é suficientemente lenta como para que poida ser considerado, na práctica, como un recurso non renovable. Particularmente, o solo de boa calidade, fértil e profundo, apto para o cultivo de fibras e alimentos útiles para a humanidade, é relativamente escaso a nivel planetario, e representa unicamente arredor dunha décima parte da superficie de terras emerxidas (Kelley, 1990). Non sorprende, polo tanto, que a súa conservación teña sido o obxectivo das políticas públicas desde hai case un século por exemplo, desde a década de 1930 nos Estados Unidos de América (Helms, 1992). Entre as medidas que os organismos públicos poden aplicar destacan as de aconsellamento aos agricultores, a cartografía das unidades do solo e do seu estado de conservación e, particularmente, as políticas de ordenamento territorial que aseguren un uso da terra acorde coas súas características (Consello de Europa, 1972; FAO, 1982). No contexto europeo, o marco 
xeral para estas políticas é o establecido pola Estratexia temática para a protección do solo (Comisión Europea, 2006a, 2006b, 2012).

Dentro do marco legal de Galicia son varios os textos que fan referencia de xeito explícito á conservación do solo como recurso limitado e non renovable. Entre estes podemos citar, por exemplo, a Lei e as Directrices de Ordenación do Territorio, a Lei de Montes, ou a Lei do Solo1. Esta preocupación non carece de sentido : estímase que arredor de 26.000 ha de terra agrícola de boa calidade foron reemprazadas por cubertas artificiais (fundamentalmente edificacións, vías de comunicación, e explotacións mineiras a ceo aberto) no período 1985-2005 (Corbelle e Crecente, 2014); e case 620.000 ha (arredor do $20 \%$ da superficie da comunidade autónoma) presentan un estado de erosión que pode ser cualificado de "grave" ou "moi grave" (MAGRAMA, 2014), sexa como consecuencia de incendios forestais previos (Vega e Fernández, 2010) ou a causa dun manexo inadecuado (Taboada et al., 2010).

Por suposto, e continuando co caso galego, existen diferentes fontes cartográficas que proporcionan información acerca do estado de conservación ou as características dos solos. Por exemplo, o Inventario Nacional de Erosión del Suelo (MAGRAMA, 2014) informa acerca do risco e da existencia real de procesos de erosión hídrica, eólica, ou por movementos en masa. Os Mapas de Clases Agrológicas, pola súa parte, serven como referencia á hora de estimar a maior intensidade de uso agrario que se podería aplicar en cada parte do territorio sen incorrer procesos erosivos de importancia (Ministerio de Agricultura, 1974). Finalmente, o Mapa de Solos de Galicia (Xunta de Galicia, 2014) ten o potencial de converterse na mellor e máis detallada fonte dispoñible en Galicia pero está limitada, no momento de escribir este texto, á cuarta parte do territorio galego. Algúns destes produtos poderían ser utilizados no proceso de elaboración de plans de ordenamento territorial: por exemplo, a Reserva Agrícola Nacional (RAN) de Portugal foi establecida empregando directamente a Carta de Capacidade do Solo portuguesa, equivalente ao Mapa de Clases Agrolóxicas español2, e temos constancia da utilización de algunha das fontes mencionadas por parte dos equipos que en Galicia se dedican á redacción de plans de ordenación municipal ${ }^{3}$. Non obstante, a traslación directa entre as clases de calquera dos produtos cartográficos mencionados e unha ou varias categorías de ordenación non está exenta de problemas, e require no seu caso do uso de determinados supostos sobre que se desexa protexer e de que modo cada mapa concreto permite aproximarse á súa identificación.
Neste traballo describiremos o proceso de preparación e posta a disposición do público dunha versión en formato dixital, utilizable nun sistema de información xeográfica, do Mapa de Capacidade Produtiva dos Solos de Galicia, coincidindo co trinta aniversario da súa publicación en papel. A intención dos autores é facilitar que as comunidades científica e técnica teñan acceso a este produto que pode resultar de interese no desenvolvemento dos seus traballos. Ao longo do texto detállase o proceso seguido na preparación da versión dixital, e proporciónase algunha información básica necesaria para futuros usuarios non familiarizados coa fonte orixinal.

\section{Materiais e método}

\section{Descrición do mapa orixinal}

O Mapa de Capacidade Produtiva dos Solos de Galicia (Díaz-Fierros e Gil, 1984) tiña como obxectivo principal a obtención dunha cartografía a escala rexional (1:200.000) que puidese servir como base da política de ordenación territorial - de feito, apareceu publicado un ano antes da aprobación da Lei 10/95 de Ordenación do Territorio de Galicia - e tomaba como guía metodolóxica a publicación $A$ Framework for Land Evaluation da FAO (1976). O mapa representa as cualidades da terra como unha acumulación progresiva de factores limitantes da produtividade. Dado que non estaba orientado a un único cultivo ou conxunto de cultivos posibles, senón á totalidade das especies vexetais que tiñan ou podían ter un aproveitamento agrícola ou forestal en Galicia, os autores consideraron inicialmente oito características de interese: (1) posibilidade de mecanización e rega; (2) espazo para enraizamento; (3) resistencia á erosión; (4) duración do período vexetativo; (5) facilidade de labor; (6) dispoñibilidade de auga; (7) dispoñibilidade de nutrientes; e (8) ausencia de toxicidades. Co fin de simplificar a lenda, as oito cualidades mencionadas aparecen agrupadas en cinco categorías: cualidades moi dificilmente modificables relacionadas co solo (1-3); cualidades moi dificilmente modificables relacionadas co clima (4); cualidades modificables relacionadas coa facilidade de labor e dispoñibilidade de auga (5-6); cualidades modificables relacionadas coa fertilidade do solo (7); e cualidades relacionadas coa presenza ou ausencia de toxicidade (8). Cada unha destas cinco categorías aparece representada na lenda por unha letra (as dúas primeiras) ou un número (as tres restantes).

1: Lei 10/1995, de 23 de novembro, de Ordenación do Territorio de Galicia, DOG de 5 de decembro; Decreto 19/2011, de 10 de febrero, por el que se aprueban definitivamente las directrices de ordenación del territorio, BOE de 23 de febrero; Lei 7/2012, de 28 de xuño, de montes de Galicia, DOG de 23 de xullo; Lei 9/2002, de 30 de decembro, de Ordenación Urbanística e protección do medio rural de Galicia, DOG de 31 de decembro.

2: A RAN foi declarada polo Decreto-Lei 196/89, como a suma de tódalas áreas incluídas nas tres primeiras clases (A, B, e Ch) dos mapas de capacidade do solo a escala 1:25.000. Coa aprobación do Decreto-Lei 73-2009 unha nova cartografía do solo realizada con criterios da FAO substitúe ás cartas de capacidade na delimitación da RAN, pero na práctica estas últimas continúan a ser a referencia na maior parte do país onde a nova cartografía aínda non foi elaborada.

3: Por exemplo, os equipos redactores dos plans de Cervantes, Portomarín, Guitiriz ou Castroverde. 
Durante a elaboración do material orixinal, os autores levaron a cabo un extenso traballo de campo para establecer sobre o terreo as transicións entre os diferentes parámetros considerados, seguido dun proceso de interpretación visual sobre fotografías aéreas e unha síntese final sobre as follas do mapa topográfico nacional 1:50.000 (MTN50), antes da súa publicación a escala 1:200.000. Para facilitar a consulta e utilización da versión dixital, incluímos un resumo da interpretación da lenda no apéndice situado ao final deste traballo.

\section{Dixitalización e vectorización}

O material de partida para o proceso de dixitalización estivo formado na súa maior parte polas copias orixinais, en papel vexetal, empregadas nos anos oitenta para a elaboración do mapa orixinal (figura 1). Como xa se indicou, estas estaban organizadas seguindo a cuadrícula do MTN50. Desafortunadamente unha parte deste material orixinal perdeuse co transcurso do tempo - en concreto, o correspondente a 10 cuadrículas, o que supón aproximadamente $015 \%$ da superficie da comunidade autónoma. Nestes casos recorreuse ao mapa publicado en papel en 1989 a escala 1:200.000 (figura 2). En ámbolos dous casos, o material foi dixitalizado cun escáner con capacidade para aceptar documentos a tamaño $\mathrm{A} 0$, e cunha resolución de 0'5 mm/píxel, suficiente para capturar adecuadamente o grosor das liñas e ao mesmo tempo non tan detallada como para incrementar demasiado o tamaño dos arquivos resultantes. Para o conxunto das operacións descritas a continuación empregamos unha combinación de varios sistemas de información xeográfica, nomeadamente GRASS GIS (GRASS Development Team, 2012), QGIS (QGIS Development Team, 2013), e ArcGIS (ESRI, 2011).
Tanto as copias de papel vexetal a escala 1:50.000 como o mapa publicado en 1989 a escala 1:200.000 presentan vantaxes e inconvenientes para o seu procesado. En particular, descoñecemos o sistema de proxección e sistema de referencia das primeiras, mentres que da segunda fonte sabemos que foi realizado en proxección UTM, e co sistema de referencia europeo de 1950 (ED50: elipsoide Internacional de Hayford de 1924, datum Potsdam). A escala, pola súa parte, é máis detallada nas primeira fonte que na segunda, pero aquela era un produto intermedio do proceso de traballo mentres que a segunda é un produto final.

Por outra parte, as follas a escala 1:50.000 inclúen as marcas de referencia da cuadrícula do MTN50 (as catro esquinas) de xeito que estas poden ser utilizadas no proceso de xeorreferenciación, utilizando como guía a división en cuadrículas do MTN50 dispoñible no centro de descargas do Instituto Geográfico Nacional (IGN), en proxección UTM e sistema de referencia ED50. En particular, dado o tipo de distorsións que poderían estar presentes nas copias escaneadas, escollemos para este proceso unha transformación afín, que permite rotar, cambiar a escala en $x$ e $y$, e trasladar en $x$ e $y$ a imaxe orixinal (Schowengerdt, 2007). A combinación dunha escala máis detallada e unha xeorreferenciación máis precisa permitía obter un produto cartográfico con mellor calidade xeométrica que no caso do mapa a escala 1:200.000, no que ao menor detalle da publicación se suma o feito de que os únicos puntos útiles para a xeorreferenciación veñen dados pola posición das principais vilas de Galicia, representadas por un simple punto de varios milímetros de grosor na fonte orixinal. Nos casos onde foi necesario recorrer a esta segunda fonte, a referencia empregada foi o centroide aproximado de cada vila no MTN50.

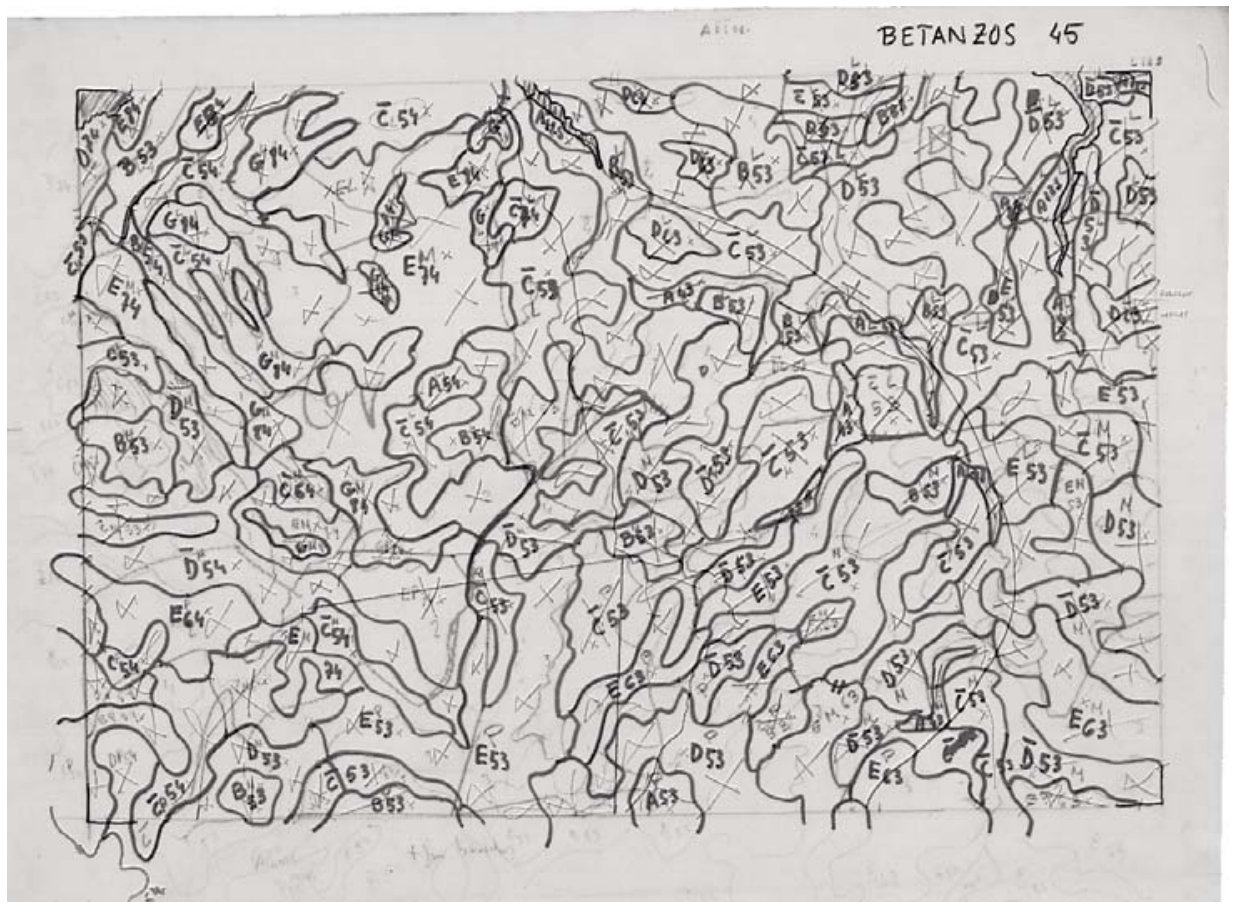

Figura 1.- Unha das follas en papel vexetal que constituíron o material principal do traballo 


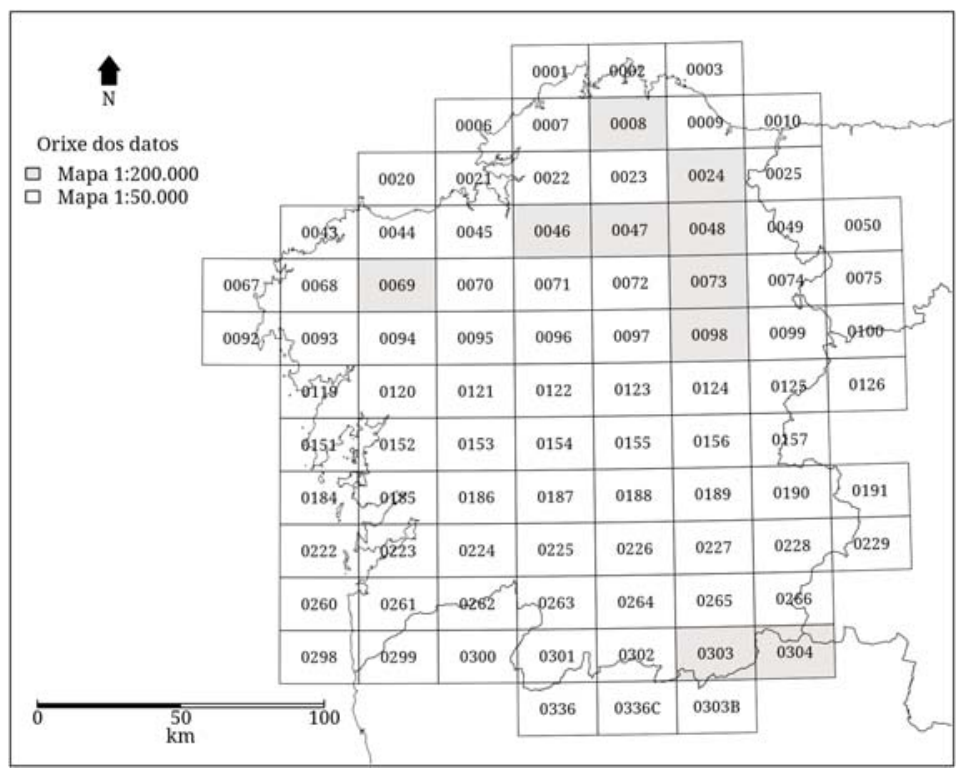

Figura 2.- Localización das cuadrículas nas que a fonte principal foi o mapa a escala 1:200.000 (elab. propia)
Polo contrario, se ben o material a escala 1:50.000 permite obter un produto final con maior precisión xeométrica, o proceso de vectorización tivo que ser realizado de xeito totalmente manual sobre a pantalla. Unicamente nas áreas nas que foi necesario recorrer ao mapa en papel a escala 1:200.000 (como xa dixemos, arredor do $15 \%$ da superficie total da comunidade) o trazado das liñas era moito máis limpo e isto permitiu empregar unha técnica de vectorización semiautomática. Neste caso, procedeuse a illar os píxeles das liñas (máis escuros que o seu entorno) mediante a utilización dun valor limiar (threshold) que os separase do fondo. Tratándose de separar liñas negras sobre un fondo branco, son varios os valores que poden ser empregados con similares resultados, dado que os valores dos niveis dixitais das liñas e do fondo están usualmente moi separados. O valor pode depender, a maiores, do estado de conservación da copia orixinal e dos axustes do proceso de escaneado. As liñas separadas do fondo foron simplificadas para a continuación convertelas de xeito automático en liñas vectoriais e realizar finalmente unha depuración manual do resultado que asegurase a conectividade das liñas formadas e eliminase os segmentos inconexos. O proceso está descrito para unha primeira versión dixital do mapa de capacidade, realizada por Sarmiento e Corbelle (2009) 4 .

Co obxectivo de asegurar a consistencia con outras fontes cartográficas, o límite da comunidade autónoma foi axustado para corresponder cos límites oficiais publicados a través do proxecto CartoCiudad 5 . Estes comprenden numerosas illas de pequena extensión, inexistentes nas fontes orixinais manexadas, que foron mantidas na xeometría do mapa dixital resultante, e codificadas na táboa de atributos co texto "illa".

Os códigos correspondentes á clasificación de cada un dos polígonos vectorizados foron asignados manualmente, tomando como fonte principal as copias en papel vexetal. En caso de discrepancias entre os códigos asignados a un mesmo polígono en follas contiguas, ou de dúbidas na interpretación, empregouse o mapa publicado a escala 1:200.000 como respaldo. Os atributos de cada polígono conteñen o código completo e o valor por separado de cada unha das cinco variables que o compoñen. A publicación orixinal en papel incluía unha táboa de conversión entre as clases do mapa e a aptitude produtiva ("o grao de adecuación da terra para un uso determinado", Rossiter, 1996) para o cultivo de millo, prados e piñeiro bravo de acordo en cinco categorías ordenadas de acordo co esquema proposto pola FAO (1976): desde as máis aptas (A1, A2, A3), ata as marxinais (N1), ou non aptas (N2) para un uso concreto. Os valores de aptitude para estes tres cultivos foron tamén incluídos como atributos de cada polígono.

O mapa vectorial resultante foi sometido a diversos controis de calidade na topoloxía para solucionar problemas de encaixe entre os polígonos de follas veciñas, e para asegurar que non quedaban espazos sen codificar no produto final. Finalmente, este foi transformado ao sistema xeodésico de referencia ETRS89, oficial en España desde $2007^{6}$, con proxección UTM, fuso 29 norte, utilizando a grella para cambio de datum en formato NTV2 distribuída polo IGN.

4: Este proceso, descrito en detalle no documento de traballo citado, implicou o uso dos seguintes módulos de GRASS GIS: r.mapcalc, r.thin, e r.to.vect. A depuración manual posterior foi realizada en QGIS e ArcGIS.

5: http://www.cartociudad.es/portal/

6: Real Decreto 1071/2007, de 27 de xullo, polo que se regula o sistema xeodésico de referencia oficial en España, BOE de 29 de agosto. 


\section{Resultados e discusión}

Como resultado da vectorización manual obtívose unha capa de información en formato vectorial con 6.804 polígonos, cun total de 327 códigos de capacidade produtiva diferentes (figuras 3 e 4). O produto ponse a disposición do público en formatos de uso habitual nos sistemas de información xeográfica como o shapefile e o keyhole markup language (formato vectorial estándar adoptado polo Open Geospatial Consortium) e poderá ser descargado no sitio web do Sistema de Información Territorial da Universidade de Santiago?. O sistema xeodésico de referencia é o ETRS89, proxección UTM, fuso 29 norte.

Estimamos que as áreas do mapa procedentes da versión 1:200.000 teñen asociado un erro medio cuadrático de 150 metros na súa posición, o que aconsella precaución á hora de empregar esta información en traballos detallados. En todo caso este é un problema que afecta só ao $15 \%$ da área total: no resto do mapa, o erro medio cuadrático derivado da xeorreferenciación estímase en menos de 50 metros. Trátase evidentemente dun erro elevado se o comparamos co que é habitual nas fontes cartográficas máis modernas. Por exemplo, o mapa de solos de Galicia, actualmente en proceso de elaboración, publícase a escala 1:50.000, do que podemos esperar un erro medio cuadrático de aproximadamente $12,5 \mathrm{~m}$. En todo caso debemos considerar neste sentido dous aspectos fundamentais: que se trata dun produto orixinalmente pensado para ser empregado en papel, a escala 1:200.000, e con trinta anos de antigüidade; e o feito de que non é infrecuente que mapas máis modernos teñan escalas similares ou incluso descoñecidas (Hartemik et al., 2012). Por outra parte, a calidade da clasificación temática (é dicir, o feito de asignar a categoría de solo correcta en cada caso) tamén é relevante. Desafortunadamente, son moi escasos os casos de mapas temáticos que proporcionan unha estimación desta calidade, como é este o caso.

Desde o punto de vista da súa utilidade, entendemos que estamos ante un produto de relevancia para as comunidades científica e técnica, aínda que só fose pola inexistencia de fontes de información alternativas. Cremos que a calidade do produto final é suficiente para ser empregada no ámbito da planificación e ordenación territorial, particularmente no contexto dos Plans Xerais de Ordenación Municipal, nos procesos de valoración para a expropiación, ou nos proxectos de reforma das estruturas agrarias (por exemplo, pero non exclusivamente, os de concentración parcelaria). No contexto da investigación, diferentes variantes derivadas da versión en papel deste mapa teñen sido utilizadas para caracterizar, por exemplo, os cambios de uso da terra nos últimos decenios (Corbelle e Crecente, 2014), a relación entre os asentamentos humanos e o seu entorno na Idade Media (Sánchez, 2008), ou o uso potencial do territorio na antigüidade (Currás, 2014).

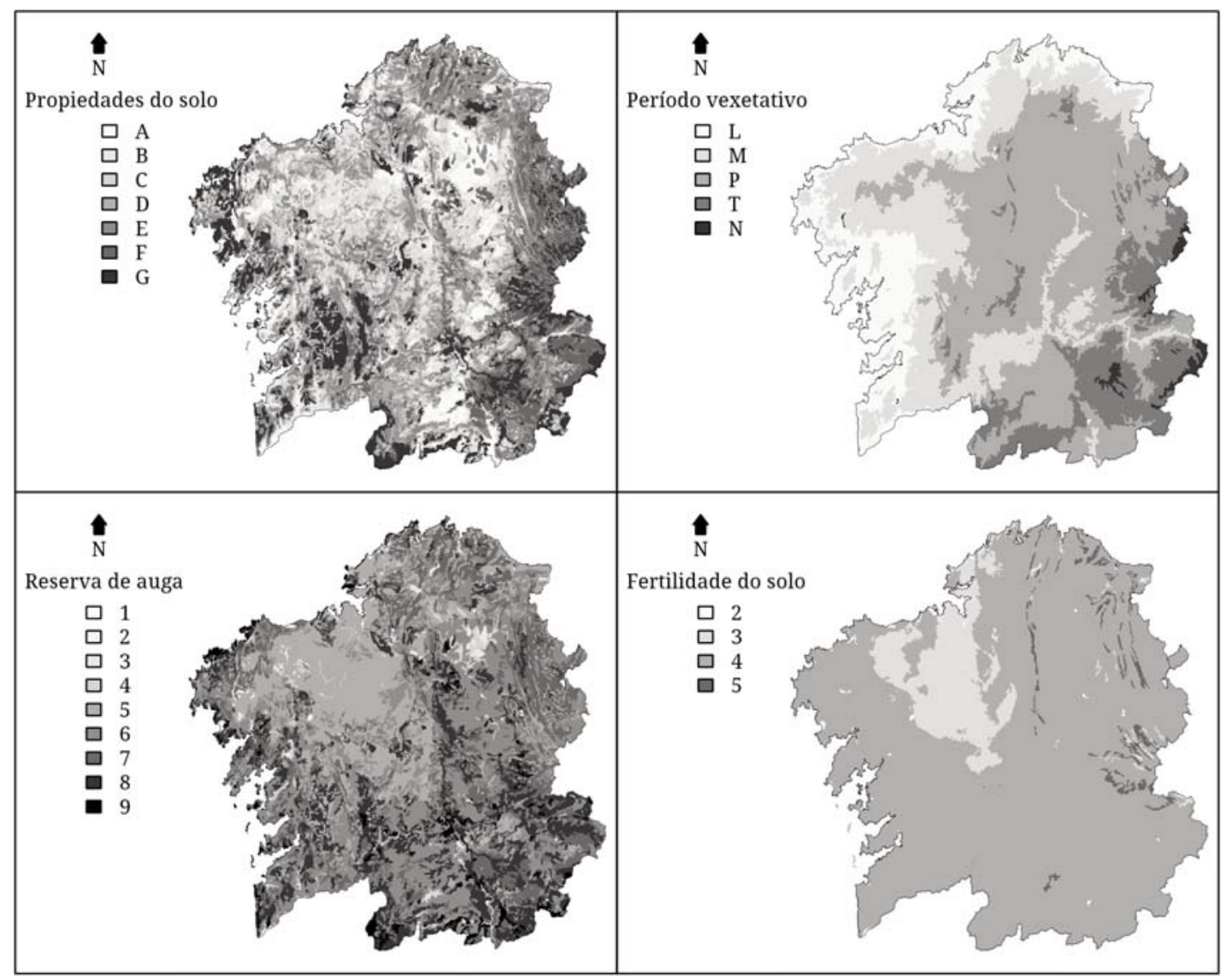

Figura 3.-

Representación das principais variables do mapa. A lenda de cada variable correspóndese coa que pode ser consultada no apéndice (elab. propia)

7: http://sit.usc.es 


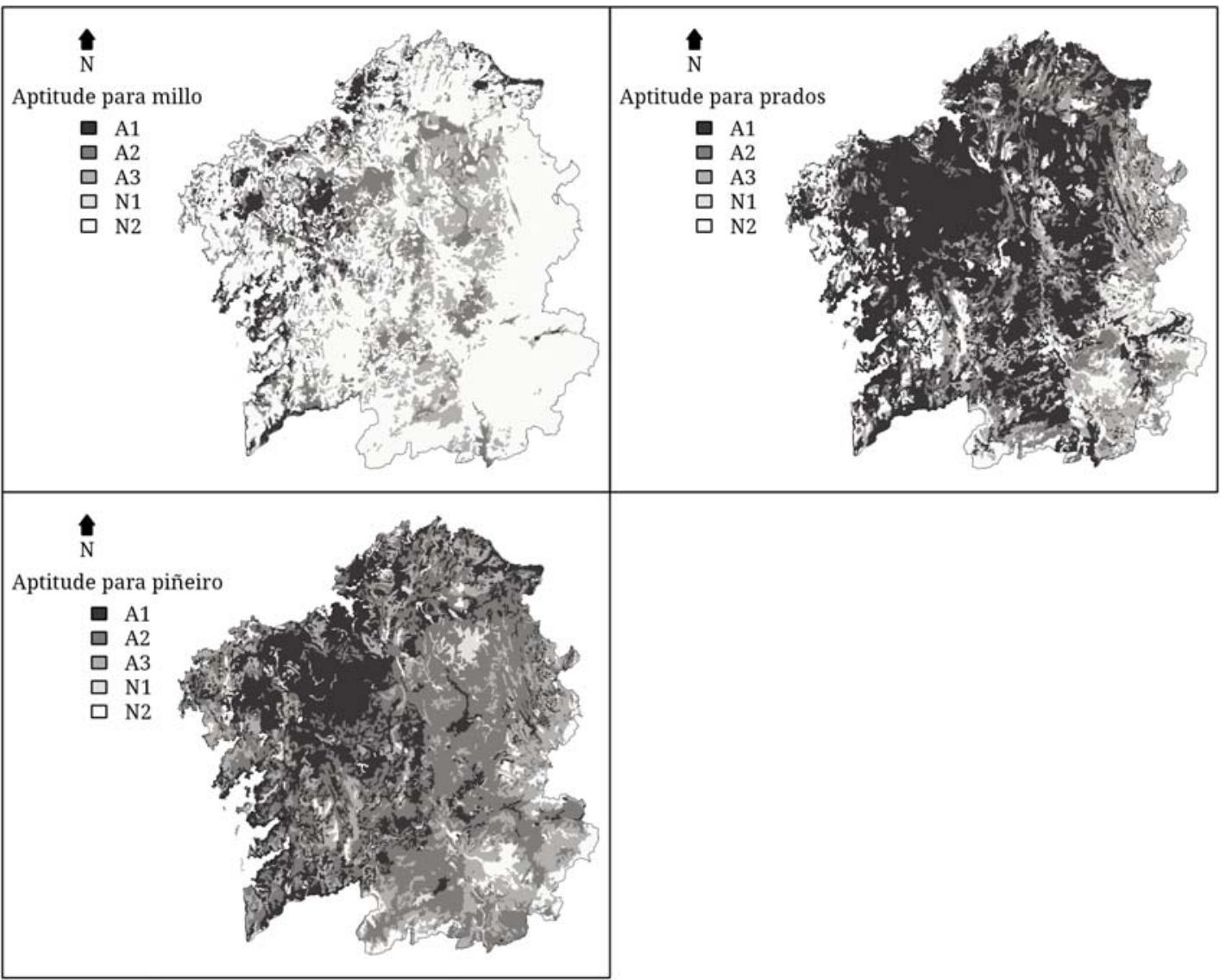

Figura 4.-

Representación da aptitude para diferentes cultivos, onde $\mathrm{A} 1$ é a clase máis apta e $\mathrm{N} 1 \mathrm{e}$ N2 son clases non aptas (elab. propia)
Na publicación da versión dixital empregamos o concepto de datos abertos (open data), entendendo por tales os que poden ser libremente utilizados e redistribuídos por calquera usuario (Open Knowledge Foundation, 2012). En particular, seleccionamos a licencia Open Database License (ODbL), que permite que os usuarios utilicen libremente os datos coas únicas restricións de citar axeitadamente a fonte de orixe e distribuír, se fora o caso, os produtos derivados baixo unha licencia do mesmo tipo ${ }^{8}$. O paquete de información dispoñible para descarga comprenderá o ficheiro vectorial do mapa, un ficheiro vectorial auxiliar coa división en cuadrículas do MTN50 para indicar a procedencia dos datos orixinais, un resumo da metodoloxía empregada, e un ficheiro de texto coa información básica de licencia e formato de cita.

\section{Conclusión}

Como resultado do proceso descrito neste documento, ponse a disposición do público a versión dixital dunha contribución á cartografía de solos que está xa no seu trixésimo aniversario. O esforzo investido na produción e libre distribución desta versión paga a pena, na nosa opinión, por tratarse dunha obra que continúa vixente a pesar do paso do tempo e que aínda pode ser de utilidade en aplicacións diversas, como por exemplo a elaboración de 8: http://opendatacommons.org/licenses/odbl/summary/ plans de ordenación do territorio, plans xerais de ordenación municipal, ou a valoración de terras en procesos de expropiación ou concentración parcelaria. Agardamos, polo tanto, que a publicación desta versión dixital sexa unha oportunidade para aproveitar o potencial da publicación orixinal.

Agradecementos Queremos expresar o noso agradecemento aos autores do mapa inicial por termos facilitado o acceso ao material orixinal, sen o que este traballo non sería posible, así como ao Servizo de Publicacións da Universidade de Santiago de Compostela por ter permitido o uso da versión publicada en 1984. Tamén nos gustaría manifestar a nosa gratitude e cariño a Dori Sarmiento, Alicia Cañizares e Fernando Miranda, por ter colaborado no proceso en diferentes momentos.

\section{Bibliografía}

Comisión Europea (2006a). Comunicación de la Comisión al Consejo, al Parlamento Europeo, al Comité Económico y Social Europeo y al Comité de las Regiones - Estrategia temática para la protección del suelo. $\operatorname{COM(2006)} 231$ final.

Comisión Europea (2006b). Propuesta de Directiva del Parlamento Europeo y del Consejo por la que se establece un marco para la protección del suelo y se modifica la Directiva 2004/35/CE. COM/2006/0232 final. 
Comisión Europea (2012). Informe de la Comisión al Parlamento Europeo, al Consejo, al Comité Económico y Social Europeo y al Comité de las Regiones. Aplicación de la Estrategia Temática para la Protección del Suelo y actividades en curso. COM/2012/046 final.

Consello de Europa (1972). Resolución (72) 19. European Soil Charter.

Corbelle Rico, E. e Crecente Maseda, R. (2014). Urbanización, forestación e abandono: cambios recentes na paisaxe de Galicia. Revista Galega de Economía, 23 (1), pp. 35-51.

Currás Refojos, B.X. (2014). Mapa de usos potenciales de la tierra de Galicia. Una perspectiva arqueológica. Trabajos de Prehistoria, 71 (1), pp. 23-41.

Díaz-Fierros Viqueira, F. e Gil Sotres, F. (1984). Capacidad productiva de los suelos de Galicia. Servizo de Publicacións, Universidade de Santiago de Compostela.

ESRI (2011). ArcGIS Desktop: Release 10. Redlands, CA: Environmental Systems Research Institute.

FAO (1976). A framework for land evaluation. Soils Bulletin, $\mathrm{n}^{\circ}$ 32. Food and Agriculture Organization of the United Nations.

FAO (1982). World soil charter. Food and Agriculture Organization of the United Nations.

Hartemink, A.E., Lowery, B., e Wacker, C. (2012). Soil maps of Wisconsin. Geoderma, 189-190, pp 451-461.

Helms, D. (1992), The development of the Land Capability Classification. En: D. Helms (ed.), Readings in the History of the Soil Conservation Service, Soil Conservation Service, U.S. Dept. of Agriculture, Washington D.C.

GRASS Development Team (2012). Geographic Resources Analysis Support System (GRASS) Software, Version 6.4.2. Open Source Geospatial Foundation. http://grass.osgeo.org

Kelley, H.W. (1990). Keeping the land alive. Soil erosion: its causes and cures. Soils Bulletin, $n^{\circ} 50$. Food and Agriculture Organization of the United Nations.

MAGRAMA (2014). Inventario Nacional de Erosión del Suelo. URL: http://www.magrama.gob.es/es/biodiversidad/temas/inventa rios-nacionales/

Ministerio de Agricultura (1974). Caracterización de la capacidad agrológica de los suelos de España. Metodología y normas. Madrid.

Open Knowledge Foundation (2012). Open data handbook documentation (release 1.0.0). Dispoñible en http://opendatahandbook.org/.

QGIS Development Team (2013). QGIS Geographic Information System. Open Source Geospatial Foundation Project. http://qgis.osgeo.org

Rossiter, D.G. (1996). A theoretical framework for land evaluation. Geoderma 72, 165-202.
Sarmiento Prieto, D.I. e Corbelle Rico, E. (2009). Dixitalización do mapa de capacidade produtiva do solo de Galicia a escala 1:200.000. Laboratorio do Territorio, Universidade de Santiago de Compostela. Documento de traballo non publicado.

Sánchez Pardo, J.C. (2008). Territorio y poblamiento en Galicia entre la antigüedad y la plena Edad Media. Tese de doutoramento, Universidade de Santiago de Compostela.

Schowengerdt, R.A. (2007). Remote sensing: models and methods for image processing ( $3^{a}$ ed.), Academic Press, Burlington, MA.

Taboada Castro, M.T., Taboada Castro, M.M., e Rodríguez Blanco, M.L. (2010). Erosión hídrica en suelos agrícolas. En Fra Paleo, U. (Ed.), Riesgos naturales en Galicia. El encuentro entre naturaleza y sociedad, pp. 183-202. Servizo de publicacións e intercambio científico, Universidade de Santiago de Compostela.

Vega, J.A. e Fernández, C. (2010). Riesgos hidrológicos y erosivos después de los incendios forestales. En Fra Paleo, U. (Ed.), Riesgos naturales en Galicia. El encuentro entre naturaleza y sociedad, pp. 79-102. Servizo de publicacións e intercambio científico, Universidade de Santiago de Compostela.

Xunta de Galicia (2014). Mapa de Solos de Galicia 1:50.000. Dispoñible en: http://siam.cmati.xunta.es/mapa-de-solos

\section{Apéndice}

Reproducimos a continuación unha breve descrición das clases consideradas no mapa co fin de facilitar a súa interpretación por parte dos usuarios. A información presentada é simplemente unha versión reducida da contida na publicación orixinal, polo que pode ser necesaria a consulta desta última.

As características contempladas na lenda aparecen agrupadas en cinco categorías: cualidades moi dificilmente modificables relacionadas co solo (cadro 1), cualidades moi dificilmente modificables relacionadas co clima (cadro 2), cualidades modificables relacionadas coa facilidade de labor e dispoñibilidade de auga (cadro 3), cualidades modificables relacionadas coa fertilidade do solo (cadro 4); e cualidades relacionadas coa presenza ou ausencia de toxicidade (cadro 5).

No caso particular das cualidades relacionadas co solo, Díaz-Fierros e Gil (1984) consideraron necesario ter en conta os cambios da profundidade e a pendente do solo introducidos pola acción humana despois de moitos anos de cultivo. Así, cando unha clase resulta mellorada para o cultivo (por exemplo se se incrementa da profundidade e suaviza a pendente mediante a construción de bancais) pasa a ser representada pola clase superior, se ben matizada por unha barra superior que indica a súa orixe antrópica: por exemplo, un solo de clase E mellorada pola acción do cultivo aparece representado como clase D. Esta regla ten como excepción ás clases $A, B$ e $C$, xa que se considera que teñen suficiente profundidade e escasa pendente como para ser melloradas polo cultivo. Estas 
clases melloradas aparecen codificadas na versión dixital cunha letra minúscula.

No caso do réxime hídrico, algúns dos polígonos do mapa aparecen na lenda con dous números simultaneamente (por exemplo EP3/84): trátase dos solos tipo pelosol, localizados fundamentalmente na Terra Chá e outras depresións terciarias de Galicia, nos que coexisten circunstancias de exceso de auga no inverno e de déficit no verán, motivo polo cal aparecen representados mediante a clase mixta $3 / 8$ (clase 3 de exceso de auga e clase 8 de déficit).

Cadro 1: Características edáficas dificilmente modificables (clases de solo e sitio)

Clase Descrición

A Solos que permiten todo tipo de mecanización e con profundidade suficiente para calquera tipo de vexetación. Admiten rega superficial sen limitacións. Sen ningún risco ou co risco lixeiro de erosión. Solos sen limitacións para a mecanización, pero con moderadas limitacións por profundidade para

B os cultivos de enraizamento profundo. Rega superficial con poucas limitacións. Ou ben de suficiente profundidade para calquera tipo de cultivo pero con limitacións para a rega superficial de gravidade. Risco de erosión de nulo a moderado.

Solos sen limitacións para a mecanización pero con limitacións para a rega superficial por gravidade e para cultivos de enraizamento profundo. Ou ben solos con limitacións para a

C maquinaria pesada pola existencia de afloramentos e con lixeiros problemas en canto a profundidade e/ou posibilidades de rega superficial por gravidade. Riscos de erosión de nulos a

moderados. que está impedida a utilización de maquinaria pesada na maior parte dos casos pola existencia de afloramentos rochosos e/ou por exceso de pendente. En xeral con profundidades intermedias que limitan o crecemento de plantas de enraizamento profundo. Risco de erosión moderado.

Solos que só permiten a utilización de maquinaria manual ou de tracción animal e con profundidades que varían de superficiais a profundas. Ou ben solos que admiten aplicación de maquinaria lixeira pero que o seu aproveitamento está limitado ou ben por pendentes ou afloramentos excesivos, ou riscos de erosión graves. Ou ben solos que admiten a aplicación de maquinaria pesada pero que están fortemente limitados por unha escasa profundidade, sendo o risco de erosión de nulo a grave. Solos de tipo marsh costeiros.

Solos que só admitirían a utilización de maquinaria manual ou forestal. As limitacións virían dadas ou pola gran abundancia de afloramentos rochosos e/ou por pendentes demasiado abruptas. Normalmente con risco grave de erosión.

G Solos que non soportarían ningún tipo de mecanización ou ben solos cunha profundidade que dificultaría o enraizamento de calquera especie vexetal. Risco de erosión variable.

Cadro 2: Duración do período de risco de xeadas

\begin{tabular}{ccc} 
Clase & Descrición & Risco de xeadas \\
\hline $\mathrm{L}$ & Limoeiro & $<3$ meses \\
\hline $\mathrm{M}$ & Millo & $3-6$ meses \\
\hline $\mathrm{P}$ & Pataca & $6-7,5$ meses \\
\hline $\mathrm{T}$ & Trigo & $7,5-9$ meses \\
\hline $\mathrm{N}$ & Nardus & $>9$ meses
\end{tabular}

Cadro 3: Réxime hídrico

\begin{tabular}{ll} 
Clase & Descrición \\
\hline 1 & Solos somerxidos o con submersión case permanente. Solos tipo marsh. \\
\hline 2 & $\begin{array}{l}\text { Solos con capa freática alta, case permanente ou solos fortemente arxilosos } \\
\text { con baixa condutividade hidráulica. Solos gley. }\end{array}$ \\
\hline 3 & $\begin{array}{l}\text { Solos con capa freática alta pero que desaparece en verán. Solos seudogley, } \\
\text { anmoor ou pelosol. }\end{array}$ \\
\hline 4 & $\begin{array}{l}\text { Solos con capa freática en superficie ocasional con condicións de boa drenaxe } \\
\text { natural. Solos típicos de terrazas fluviais actuais. }\end{array}$ \\
\hline 5 & Solos ben drenados e con menos de 30 días de déficit de precipitación. \\
\hline 6 & Solos ben drenados e con déficit de precipitación de 30 a 60 días. \\
\hline 7 & Solos ben drenados e con déficit de precipitación de 60 a 90 días. \\
\hline 9 & Solos ben drenados e con déficits de precipitación de 90 a 120 días. \\
\hline
\end{tabular}


Cadro 4: Dispoñibilidade potencial de nutrientes

\begin{tabular}{|c|c|}
\hline Clase & Descrición \\
\hline 1 & $\begin{array}{l}\text { Solos con unha dispoñibilidade potencial de nutrientes óptima. En xeral con } \\
\text { saturacións superiores ó } 75 \% \text { e } \mathrm{pH} \text { máis altos que } 6,5 \text {. Practicamente non } \\
\text { existen en Galicia. }\end{array}$ \\
\hline 2 & $\begin{array}{l}\text { Dispoñibilidade po tencial de nutrientes boa. En xeral con saturación do } \\
\text { complexo de cambio superior ó } 50 \% \text { e pH maiores de } 5,5 \text {. Solos marsh e } \\
\text { sapropel. }\end{array}$ \\
\hline 3 & $\begin{array}{l}\text { Dispoñibilidade potencial de nutrientes moderada. Saturación do } 50 \text { ó } 15 \% \text { e } \\
\text { pH en xeral superiores a } 5 \text {. Solos sobre caliza } \quad \text { s, rocas básicas e xistos do } \\
\text { complexo de Ordes. }\end{array}$ \\
\hline 4 & $\begin{array}{l}\text { Dispoñibilidade potencial de nutrientes mala. Saturación do } 25 \text { ó } 7 \% \text { e pH de } \\
4,5 \text { a } 5,0 \text {. Solos derivados de rochas graníticas e xistos que non pertenzan ó } \\
\text { complexo anterior. Solos derivados de materiais sedim entarios arxilosos ou } \\
\text { limosos. }\end{array}$ \\
\hline 5 & $\begin{array}{l}\text { Dispoñibilidade potencial de nutrientes moi mala. Saturación inferior ó } 7 \% \text { e } \\
\mathrm{pH} \text { menores de } 4,5 \text {. Solos derivados de areniscas, cuarcitas e materiais } \\
\text { sedimentarios con forte predominio de areas ou coluvios de cuarzo. }\end{array}$ \\
\hline
\end{tabular}

Cadro 5: Toxicidade ou salinidade

Clase Descrición

s Solos con toxicidades por salinidade. Zonas de solos marsh que presentan en xeral unha condutividade do extracto de saturación superior a $8 \mathrm{mmhos} / \mathrm{cm} \mathrm{e}$ xeralmente superior a $16 \mathrm{mmhos} / \mathrm{cm}$ nas zonas máis influídas $\mathrm{p}$ olas mareas (sapropel).

n Solos con toxicidades por níquel. Solos derivados de serpentinitas, nos que xeralmente se encontran cantidades de níquel asimilable (en ácido acético 2,5 $\% \mathrm{pH} 2,5)$ superiores a $11 \mathrm{ppm}$. 